\title{
JUSTICIA GLOBAL, JUSTICIA LEGAL E IMPERIO DE LA LEY
}

\author{
Isabel Turégano \\ Universidad de Castilla-la Mancha
}

\section{UNA CONCEPCIÓN POLÍTICO-JURÍDICA DE LA JUSTICIA GLOBAL}

a Teoría de la justicia sigue anclada en nuestro país, en gran medida, en los presupuestos de un limitante nacionalismo metodológico. No se escribe mucho en nuestra disciplina sobre justicia global ni sobre sus imbricaciones jurídicas, a pesar de la necesidad de ambas para actualizar nuestros conceptos e ideas heredados. Francisco LAPORTA y Liborio HIERRO, sin embargo, han formulado reflexiones relevantes y estimulantes sobre ellas. Sus planteamientos sobre la justicia global tienen el mérito añadido de plantear una concepción política de la misma, que resulta más adecuada para comprender la complejidad de problemas y traducirlos en los temas y conceptos de la iusfilosofía ${ }^{1}$.

LAPORTA y HIERRO parten de un mismo presupuesto esencial: para la realización de los principios cosmopolitas es fundamental un orden jurídico global capaz de hacerlos efectivos. Ambos presuponen que ese orden jurídico no existe y que esta es una de las causas de las graves injusticias globales. En sus escritos, los problemas fundamentales de la justicia global se traducen, en último término, en problemas políticojurídicos relativos a la construcción y legitimación de ese orden. Liborio HIERRO habla de la fundamentación moral del derecho de todos a un orden institucional con poder coercitivo para garantizar los derechos humanos. Francisco LAPORTA plantea la necesidad de buscar modos de realizar el ideal del imperio de la ley en el contexto de interrelaciones globales.

Liborio HIERRO emplea específicamente el lenguaje de la justicia global. Entiende que los problemas globales suscitan auténticas demandas y pretensiones que deben ser comprendidas en términos de justicia y no solo humanitarias o morales, esto es, demandas cuyo cumplimiento es de tal relevancia moral para la convivencia social que generan obligaciones generales cuya imposición requiere una estructura coercitiva. Creo que las ideas que maneja HIERRO de riesgos comunes, daños y carencias generan, como él plantea, no tanto problemas de justicia conmutativa o distributiva cuanto un

1 Estas páginas son una reflexión sobre dos trabajos de los profesores homenajeados: L. HIERRO, «Justicia global y justicia legal. ¿Tenemos derecho a un mundo justo?», en A. RuIZ MiguEL (ed.), Entre Estado y cosmópolis, Madrid, Trotta, 2014, 83-120; y F. LAPORTA, «Imperio de la ley y globalización», en El imperio de la ley. Una visión actual, Madrid, Trotta, 2007, 243-265. Las páginas que aparecen en el texto entre paréntesis corresponden a estas obras. 
deber general de actuar en favor de la reforma de las estructuras sociales y políticas que los han generado. Efectivamente, las obligaciones colectivas no pueden traducirse en actos ocasionales de rescate fundados en argumentos humanitarios, sino en la creación progresiva y coordinada de estructuras institucionales que garanticen el adecuado cumplimiento de los deberes positivos básicos. «En ausencia de instituciones justas», afirma Pablo GILABERT, «la prioridad primera es crearlas en lugar de reincidir en la asistencia informal» ${ }^{2}$.

Las argumentaciones de LAPORTA y HIERRO se apoyan en exceso, sin embargo, en la dimensión formal de esta concepción política de la justicia, centrando su justificación en la necesidad de que se instaure formalmente un orden para la garantía de los derechos. De ahí su insistencia en que, también en la esfera global, deba existir un «monopolio institucional de la fuerza legítima en manos de una institución política supraestatal» (HIERRO: 97, 98-99, 116) y su común referencia a Thomas HOBBES como punto de partida. Pero interpretar la justicia global como esencialmente política tiene una dimensión subjetiva relevante que puede implicar consecuencias algo diferentes. La necesidad de crear instituciones supraestatales justas va necesariamente vinculada a la exigencia de que todos puedan participar en el proceso de su creación como individuos que se reconocen mutuamente igual dignidad ${ }^{3}$.

La dimensión estructural o institucional de la injusticia no supone solo un problema de diseño de un orden legal sino también el reconocimiento de todo individuo como agente activo en su configuración, evitando considerar a los más desfavorecidos meros receptores de justicia. La situación actual de pobreza y privación de muchos seres humanos no obedece solo a que carezcan de los medios necesarios para la subsistencia o para una vida decente, sino que son privados de tales medios por una situación de injusticia política y económica generada por estructuras de poder en cuya configuración no tienen capacidad de influir ${ }^{4}$.

HIERRO reconoce que la necesidad conceptual de un orden legal para poder hablar de justicia distributiva y conmutativa remite a un problema previo, el de la justificación moral del orden legal (p. 107) y apela a que «derive sus poderes legítimos del consentimiento de las personas y que tenga por objeto garantizar sus derechos morales básicos, los derechos humanos» (p. 108). Pero no llega a desarrollar esta idea central para su argumento. LAPORTA reconoce su escepticismo respecto de las posibilidades del Derecho global para realizar suficientemente el ideal del imperio de la ley (p. 254) y habla de la necesidad de crear unidades políticas y jurídicas supranacionales, de las que pone como ejemplo el de Europa, sin aludir al origen de su legitimidad ni si este sería el modelo para un orden global.

2 P. Gilabert, From Global Poverty to Global Equality. A Philosophical Exploration, Oxford, OUP, $2012,56$.

3 A. APPIAH, «Dignity and Global Duty», en Boston University Law Review, núm. 90, 2010, 671-672, 674.

4 R. Forst, «Justice, Morality and Power in the Global Context», en A. Follesdal y Th. PogGe (eds.). Real World Justice, Dordrecht, Springer, 2005, 32. 


\section{ALGUNOS DESACUERDOS: LA NECESIDAD DE UN INDIVIDUALISMO, UNIVERSALISMO Y RACIONALISMO REVISADOS}

La idea central del planteamiento de ambos autores acerca de la necesidad de una legalidad global organizada y vinculante para la realización de la justicia queda reducida a una traslación de los modelos políticos y jurídicos liberales que interpretaron los principios morales universales para el contexto estatal. Esta propuesta encuentra, a mi juicio, algunas dificultades que condicionan la validez de aquella idea central.

En primer lugar, como escribe HIERRO, la idea de justicia global no se refiere a la moralidad que ha de regir las relaciones entre los Estados sino a aquella que toma a las personas, con independencia de su pertenencia a comunidades concretas, como el foco esencial de la justicia. No obstante, incurre en algunas contradicciones cuando habla de que la justicia global «regula idealmente las relaciones entre los individuos que son ciudadanos de Estados diferentes» (p. 86) o considera que los Estados han de abandonar el estado de naturaleza para que sus miembros tengan garantizados sus derechos frente a los individuos miembros de otro grupo (p. 88). Quizá el autor es consciente de la dificultad de adoptar una perspectiva estrictamente individual y abstracta como foco esencial de la justicia global.

Si, como plantea HiERro, la reflexión sobre los principios de justicia debería comenzar por analizar el contexto actual de injusticia global es necesario reconocer que ese contexto está traspasado por múltiples relaciones mediadas por estructuras de poder que se entrecruzan y conectan. Quienes son objeto de injusticia están sujetos a relaciones de dominación diversas. Una teoría de la justicia tiene que afrontar esas relaciones de dominación plural en múltiples niveles ${ }^{5}$. Ha de ser no tanto una teoría de la justicia global como transnacional. Como tal debe proveer un principio de justificación o de legitimidad del poder que domina cada una de esas relaciones. Ese principio podría interpretarse en el sentido de que, en cualquier contexto de justicia, todas las relaciones deben estar igualmente sometidas a principios y normas que puedan ser recíproca y generalmente aceptadas por todos los afectados. Los diversos contextos de la justicia están igualmente sometidos a esta misma exigencia moral ${ }^{6}$. La justicia transnacional supone una exigencia de justificación tanto interna a cada contexto de relaciones de poder como externa respecto de las interrelaciones entre ellas.

LAPORTA asume esta transnacionalización de las interacciones globales, formales e informales, entre intereses y agentes en distintas posiciones y de las normas que las regulan, desbordando «con agilidad los límites de las fronteras» (p. 255). Como expone, el problema es que esa normatividad transnacional fluida y desterritorializada no logra satisfacer la función que corresponde al Derecho como límite al ejercicio arbitrario del poder. Los actores globales mejor situados se interesan solo por elegir bajo qué normas les resulta conveniente ampararse, sin cuestionar su legitimidad (p. 251). La consecuencia es que muchos de los regímenes normativos existentes se apartan de las exigencias del imperio de la ley pero son eficaces en la medida en que son propicias

\footnotetext{
5 R. FORST, «Towards a Critical Theory of Transnational Justice», en Metaphilosophy, vol. 32, 2001, 166.

${ }^{6}$ Ibid., 169.
} 
para el desarrollo de las actividades requeridas por quienes están en una posición de dominio.

Pero la propia pluralidad de relaciones no es necesariamente negativa. Favorece la capacidad de reflexión y de acción de un mayor número de individuos. Un cosmopolitismo abstracto, estrictamente individualista, no tiene en cuenta el peso moral de la variedad de solidaridades que moldean las experiencias personales. El desarraigo al que conduce el debilitamiento de los vínculos políticos tradicionales perjudica a los menos favorecidos, porque obvia el hecho relevante de que quienes se encuentran peor situados en el proceso de la globalización pueden tener razones especiales para comprender su lugar en el mundo y organizar su acción a través de aquellas solidaridades $^{7}$. El cosmopolitismo no puede ser ajeno a la diversidad de movimientos, redes, afiliaciones que ayudan a luchar contra la exclusión a millones de personas. Muchos pensadores identifican en nuestros días el cosmopolitismo con esos proyectos plurales de transformación desde problemas y solidaridades particulares. Se habla, así, de «cosmopolitismo vernáculo» (BHABHA), «cosmopolitismo subalterno» (SANTOS), «cosmopolitismo incrustado» (ERSKINE), «arraigado» (ACKERMAN, HOLLINGER), «parcial» (APPIAH), «contextual» (BECK), «situado» (ROBBINS).

Estos cosmopolitismos alternativos evidencian de un modo difícilmente resoluble la tensión entre la lealtad a los vínculos de solidaridad y la igualdad moral implícita a todo cosmopolitismo. Mientras el cosmopolitismo más individualista resuelve esta tensión interpretando que las obligaciones especiales se basan en consideraciones morales de orden general (reciprocidad, eficiencia en la consecución del bien universal...), muchos de los nuevos cosmopolitas estiman que esa interpretación pasa por alto el aspecto particular que confiere valor a las relaciones concretas. Es desde tales relaciones desde donde debe partirse en la búsqueda común de modelos normativos ampliados. Esto solo es posible desde la premisa cosmopolita de la «des-ontologización» del otro: la diferencia del otro no es una diferencia esencial y atemporal, sino contingente e histórica y, como tal, puede atravesarse para hacer posible el diálogo ${ }^{8}$.

En segundo lugar, los planteamientos más abstractos de la justicia global no toman realmente en serio el valor de la igualdad de cada vida humana si la consideran al margen de las situaciones y circunstancias concretas que la dotan de sentido y desde las que el individuo actúa y ejerce su responsabilidad. En este sentido, no se puede aspirar a un consenso armónico universal sino a un proceso dialéctico y abierto a la diferencia y al conflicto desde los que resignificar el sentido de los valores universales. Seyla BENHABIB ha propuesto el concepto de «iteración democrática» para dar cuenta de este tipo de procesos. En ellos, las comunidades democráticas reinterpretan los principios morales, desafiándolos y rearticulándolos de acuerdo con circunstancias cambiantes con el objetivo de preservar y enriquecer su significado originario» ${ }^{9}$. En este proceso se constituye el propio sujeto de la democracia que amplía sus formas de participación más allá de las instituciones formales en ámbitos que expanden la ciudadanía y la desnacionalizan.

\footnotetext{
7 C. CALHoun, «Belonging in the Cosmopolitan Imaginary», Ethnicities, vol. 3 (4), $2003,546$.

${ }^{8}$ U. BECK, Poder y contrapoder en la era global, Barcelona, Paidós, 2004, 70.

9 S. BenhabiB, Another Cosmopolitanism, Oxford, Oxford University Press, 60.
} 
Desde estas premisas, los derechos no son el resultado de una elaboración abstracta y racional, sino respuestas normativas, histórico-concretas a situaciones de injusticia. La dimensión igualitaria de los derechos solo es realizable progresivamente y dentro de contextos sociales. El proceso de internacionalización de los derechos muestra que solo «tendencialmente» son universales ${ }^{10}$. Mediante ese proceso se realiza una labor progresiva de interpretación de los derechos que formula sus exigencias normativas para contextos cada vez más ampliados y susceptibles de generar consenso en cuanto percibidas generalmente como mejora para la legitimidad del orden transnacional en su conjunto ${ }^{11}$.

En tercer lugar, la aspiración a un sentimiento humanista y universal (del que HIERRO habla en la p. 109) es insuficiente como base de una estructura política transnacional o global. HIERRO admitiría lealtades puramente cívicas o, incluso, prudenciales o autointeresadas. Pero un cosmopolitismo crítico asumiría la necesidad, además, de formas de identificación y motivación que conduzcan a las personas a prácticas democráticas ampliadas. Un orden legal supranacional solo es posible desde la capacidad de abrirse a los otros y la convergencia en lealtades comunes que favorezcan la creación de solidaridades y espacios para el diálogo. Ciertamente esos vínculos e identidades ampliados se pueden ir construyendo desde la progresiva consolidación de espacios formales e informales de participación transnacional. En cierto modo este es el sentido del «patriotismo multinacional global» sobre el que han teorizado autores como WEINSTOCK o HABERMAS. Ese patriotismo cívico no resulta de modo abstracto de la propia idea de humanidad, sino «de los hábitos que surgen de la participación en prácticas comunes e instituciones compartidas» ${ }^{12}$. En todo caso, creo que es un modelo demasiado abstracto de solidaridad comunal que debe reforzarse con otros que favorezcan una identificación cada vez más ampliada capaz de generar por sí mismos espacios comunes para la participación.

Por último, coincido con HierRo en que las personas tenemos la legítima pretensión de que «se establezca un orden social e internacional en el que los derechos y libertades proclamadas en la Declaración Universal se hagan plenamente efectivos, que es lo que reconoce el artículo 28», pero dudo de que ese orden pueda llegar a ser un orden jerarquizado y organizado conforme al modelo de las democracias liberales nacionales. HIERRO apela al «monopolio institucional de la fuerza legítima en manos de una institución política supraestatal» (pp. 97 y 98-99). Piensa en una estructura jerarquizada en la que la «autoridad última» cede competencias pero retiene el poder de imponer coercitivamente el orden legal. No concreta cuál es la estructura institucional que habría de tener ese orden legal orientado a la garantía de derechos.

La democracia es un fenómeno pluridimensional en el que distintos elementos y ámbitos se complementan para aproximarse al ideal de la soberanía popular. Esto

10 J. DE LUCAS, «Para una discusión de la nota de universalidad de los derechos: a propósito de la crítica del relativismo ético y cultural», Derecho y Libertades: Revista del Instituto Bartolomé de las Casas, núm. 3, 1994,270 .

${ }_{11}$ Algo similar quiere decir Ronald DwORKIN cuando habla del principio de prominencia (salience) como fundamento moral del sistema internacional en «A New Philosophy of International Law», Philosophy and Public Affairs, 41, núm. 1, 2013, 19.

12 D. WEINSTOCK, «Prospects for Transnational Citizenship and Democracy», Ethics and International Affairs, 2001, 15(2), 59. Vid. la idea de patriotismo constitucional en J. HABERMAS, «Citizenship and National Identity: Some Reflections on the Future of Europe», Praxis International, 1992, 12 (1), 1-19. 
es especialmente importante en el ámbito transnacional. Lo que exige la democracia son instrumentos de participación, espacios para la crítica, mecanismos de rendición de cuentas, instrumentos de compensación de las minorías, etc. Ello demanda diseños institucionales complejos que, cuando resultan insuficientes o ineficientes, deben completarse con espacios e instrumentos de participación informales. El ideal de la democracia puede tratar de alcanzarse a nivel global de modo progresivo mediante la mutua interacción entre factores muy diversos: el Estado como agente potencial de los principios cosmopolitas en cuanto que dispone de recursos e instrumentos de legitimación capaces de ser reinterpretados con ese fin; cauces de control y crítica desde los movimientos sociales; instrumentos informales de participación capaces de introducir problemas y perspectivas nuevas en la deliberación institucional; regímenes y organismos internacionales de defensa de derechos humanos que asuman progresivamente competencias hasta entonces estatales; complementariedad entre los instrumentos de garantía de derechos nacionales, internacionales y transnacionales etcétera.

Creo que LAPORTA es más consciente de esta necesidad de integrar distintos elementos cada uno de los cuales puede hacer aportaciones diversas para la realización del rule of law a nivel transnacional. La lex mercatoria, los principios, reglas y decisiones de la OMC, las diversas variantes del soft law... alcanzan cada uno de ellos «algunos de los objetivos de alguno de los grados de densidad del ideal del imperio de la ley» (p. 258). No obstante, cada uno de ellos y su mutua interrelación resultan insuficientes para lograr hacer efectiva la justicia global, esto es, el pleno sometimiento del poder al Derecho. Su argumentación concluye del mismo modo que la de HiERRO: la progresiva realización del ideal de justicia global supone el logro progresivo de normas legales vinculantes aplicadas por agentes imparciales que exigen la construcción de unidades políticas y jurídicas supranacionales. En ambos casos, es desde un ideal normativo desde el que se evalúa la realidad político-jurídica global o transnacional y desde el que se articula un modelo institucional para superar sus graves déficits. Lo que he tratado de mostrar es que, como ha explicado Amartya SEN ${ }^{13}$, este planteamiento trascendente que trata de construir en abstracto una teoría acerca de los principios para una sociedad perfectamente justa, obvia algunos problemas relevantes, tanto sobre la dificultad de lograr un consenso acerca del modelo ideal como los problemas relativos a la elección entre opciones subóptimas, en la que se pueden dejar fuera instrumentos que coadyuvan a una regulación transnacional más inclusiva. La tarea política de atender las injusticias reales exige no solo modelos normativos críticos sino también la búsqueda de consensos prácticos capaces de satisfacer el derecho de todos a intervenir en su justificación desde sus propias posiciones y circunstancias. Sin duda, los trabajos de LAPORTA y HIERRO contribuyen a que el debate sobre la difícil cuestión de la justicia global tenga el grado de rigor y compromiso que es necesario para orientar esa convergencia práctica.

13 A. SEn, La idea de la justicia, Madrid, Taurus, 2010.

$\triangle \quad$ DOXA EDICIÓN ESPECIAL (2017) 